\title{
FORMAÇÃO POLÍTICA DE EDUCADORES: PRESENÇA DE LÊNIN E GRAMSCI NOS CADERNOS UTILIZADOS NA ESCOLA DE FORMAÇÃO DA APP-SINDICATO DOS TRABALHADORES EM EDUCAÇÃO PÚBLICA DO PARANÁ
}

\author{
Denila Coelho ${ }^{1}$ \\ André Paulo Castanha ${ }^{2}$
}

\begin{abstract}
RESUMO
Este artigo é resultado dos estudos e pesquisas que estamos realizando sobre a Escola de Formação Política, da APP-Sindicato dos trabalhadores em Educação Pública do Paraná, entre 2007-2012. O estudo parte da análise dos cadernos utilizados para a formação dos professores procurando identificar as bases teóricas dessa formação. Assim, o objetivo é perceber como os escritos de Lênin e Gramsci foram explorados no material preparado para o estudo dos educadores. Para, além disso, também procuramos explicitar as principais ideias educativas dos dois autores sobre educação e formação política dos educadores, a partir da análise de seus escritos. Ao analisar o conteúdo dos cadernos, ainda que de forma inicial, podemos constatar o peso das obras de Lênin e Gramsci na construção dos textos utilizados para a formação política da APP-sindicato. Todavia, chamamos a atenção para a necessidade de o material explorar mais os textos dos próprios autores, ao invés de utilizar-se de intérpretes.

Palavras-Chave: Escola de Formação Política, APP-Sindicato, Educação em Lênin e Gramsci, Educação e Transformação.

\section{TRAINING PROGRAM FOR EDUCATORS: LENIN AND GRAMSCI PRESENCE IN THE EXERCISE BOOKS USED IN THE TEACHER TRAINING PROGRAMS OF APP- TEACHER UNION OF PARANA STATE.}

\begin{abstract}
This paper is the result of studies and surveys that we are doing about Parana State Teachers Union political capacity building space between 2077-2012. The study begins from the analysis of books used for teachers training, aiming to identify the theoretical basis of such training. Thus, it aims to check how the writers Lenin and Gramsci were used in the text books prepared for the study of teachers. Beyond that, we also tried to explain the main educative ideas of both authors about education and political formation of educators, from an analysis of their writings. When analyzed the content of the text books, even in a initial way, we could see the importance of Lenin and Gramsci ideas in building the texts used for the political formation of APP- union. However, we call the attention for the need of the text books explore more the original texts, instead of use the interpreters.

Keywords: Political training School; APP - Teacher Union, Education in Lenin and Gramsci, Education and Transformation.
\end{abstract}

\section{Introdução}

Este artigo é resultado dos estudos e pesquisas que estamos realizando sobre a Escola de Formação Política da APP-Sindicato entre 2007-2012.

O estudo partir da análise dos cadernos utilizados para a formação dos professores procurando identificar as bases teóricas dessa formação. Assim, o objetivo principal é perceber como os escritos de Lênin e Gramsci foram explorados no material produzido para estudo dos educadores. Para, além disso, também procuramos explicitar as principais 
ideias educativas dos dois autores, sobre educação e formação política dos educadores, a partir da análise de seus escritos.

Não se trata de buscar nesses autores respostas prontas, até porque a conjuntura atual difere muito do momento histórico vivenciado por eles. A intenção é levantar os fundamentos, conceitos e categorias nos respectivos autores, que nos possibilitem entender a função da escola e da educação nos dias atuais, para que possamos através da análise concreta, buscar mecanismos de transformação da realidade existente visando a formação omnilateral do ser humano.

Cientes de que o texto tem limitações, uma vez que os autores requerem vários anos de estudo, além de um bom entendimento do período histórico em que produziram seus escritos, para que possamos compreendê-los na sua essência, ousamos fazer alguns apontamentos sobre o uso dos escritos de Lênin e Gramsci na formação política sindical dos professores do Paraná. Para tanto, organizamos o texto em duas partes. Na primeira apresentamos algumas das proposições de Lênin e Gramsci sobre o papel da educação para a transformação social. Na segunda, apresentamos os temas tratados nos cadernos utilizados na escola de formação política da APP-Sindicato, procurando identificar como as teorias de Lênin e Gramsci embasam o conteúdo dos cadernos.

\section{Lênin e Gramsci: Educação para a formação de Dirigentes e Intelectuais}

É importante destacar que a educação aqui não é tratada como a redentora dos males sociais, uma vez que, por si só, não resolve os problemas. No entanto, acreditamos que ela pode se constituir em um importante instrumento no processo de libertação dos oprimidos.

Lênin, grande líder revolucionário russo, militante ativo, intelectual e estrategista, viveu boa parte de sua vida no exílio ou no cárcere. Seus escritos contribuíram para o aprofundamento dos estudos sobre o capitalismo, imperialismo e o Estado.

Gramsci, segundo Jinkings e Sader (2012, p. 249), foi um teórico, ativista político marxista, leitor de Marx, Engels, Lênin. Juntamente com um grupo fundou o Partido Comunista $^{3}$ Italiano (PCI). Sua maior produção se deu no cárcere, no qual passou onze anos durante o regime fascista de Mussolini. Na prisão Gramsci escreveu os Cadernos do Cárcere e redigiu muitas cartas, que posteriormente foram reunidas e publicadas como Cartas do Cárcere. Antes de ser preso escreveu muitos textos, publicados com o título de Escritos Políticos.

Neste texto são abordados dois escritos de Lênin: a obra Que fazer? Os problemas cadentes do nosso movimento, que de acordo com Jinkings e Sader (2012, p. 141), "é uma das mais importantes contribuições de Lênin ao marxismo e a mais avançada elaboração sobre o método de organização do proletariado no partido revolucionário". E o artigo: Tarefas da juventude na construção do socialismo, no qual Lênin orientou os jovens sobre o que se deveria ser aproveitado da escola burguesa para transformar a sociedade. De Gramsci utilizamos como base os Cadernos do Cárcere, mais especificamente, os intelectuais e a escola.

A frase de Lênin: "sem teoria revolucionária não há movimento revolucionário", tem sido utilizada pela Escola de Formação da APP-Sindicato ${ }^{4}$, que objetiva através de seus cursos de formação compor novos quadros dirigentes e qualificar a luta sindical. Ao buscar unir teoria e prática objetiva instrumentalizar os educadores a fim de que estes possam, com sua atuação no processo educativo, despertar nos educandos a consciência da necessidade da transformação social.

Compartilhamos da ideia de Lênin, que considera a formação teórico-política como condição para a ação revolucionária, que só se efetiva quando dialeticamente se materializa 
na prática política. Conhecer a realidade na qual estamos inseridos, o processo produtivo, do qual fazemos parte e as relações sociais que permeiam nosso dia-a-dia, não é uma tarefa fácil, pois exige muito estudo, reflexão e concentração, mas é fator essencial para qualquer mudança. Sem esse esforço intelectual nervoso, como diz Gramsci não iremos a lugar algum - estudar é trabalhar (2004, p. 51).

Nessa questão, conhecer a educação é fundamental. A discussão deve centrar-se sobre qual educação temos/precisamos? Seria uma educação transformadora ou uma educação que visa manter a ordem já estabelecida pelo capital e as classes dominantes? Sabemos que somos parte de uma sociedade de classes, na qual observamos diariamente interesses conflitantes. Fazendo uma breve análise da sociedade observamos que é uma pequena parcela da população que comanda uma ampla maioria. Teoricamente essa minoria representa os interesses de toda a população. Nos perguntamos será que isso ocorre de fato? Ou será que estamos apenas colaborando para a manutenção da sociedade como foi constituída ao longo do tempo e ainda acreditando que essa é a melhor forma de organização?

As escolas segundo Lênin não educavam os jovens operários e camponeses, apenas os preparavam para que a burguesia tivesse maiores lucros, sem perturbação do seu sossego e ociosidade. Daí a necessidade de tomar da escola burguesa apenas aquilo que era necessário para conseguir uma verdadeira educação comunista, uma vez que Lênin atribuía aos jovens o trabalho de transformar a sociedade existente. Tratando das tarefas da União das Juventudes Comunistas, Lênin ressaltou que:

Esse problema merece nossa atenção na medida em que, pode-se dizer, em certo sentido, é justamente à juventude que incumbe a verdadeira tarefa de criar a sociedade comunista, porque é evidente que a geração de militantes educada na sociedade capitalista pode, no máximo, cumprir a tarefa de destruir as bases da velha vida capitalista baseada na exploração (2005, p. 09).

A transformação social pretendida por Lênin, requer além da mudança nas estruturas, uma mudança na concepção de mundo. É um processo que exige dessa organização e das demais semelhantes, que querem passar ao comunismo a apropriação dessa teoria. Para não haver disparidade entre o que se diz e o que se faz é necessário aliar teoria e prática impedindo assim, essa contradição.

Sem trabalho, sem luta, o conhecimento livresco do comunismo, adquirido em folhetos e obras comunistas, não tem absolutamente nenhum valor, uma vez que não faria mais que continuar o antigo divórcio entre a teoria e a prática, esse mesmo divórcio que constituía o mais repugnante traço da velha sociedade burguesa (LÊNIN, 2005, p. 1112).

Nesse ponto de vista, a escola necessita dar aos jovens fundamentos da ciência, da arte, possibilitando a estes, criarem por si mesmos uma mentalidade comunista, fazendo deles homens cultos e participantes na luta para se libertarem dos exploradores (LÊNIN, 2005, p. 25).

Ao tomarmos como base as reflexões de Lênin, entendemos que a escola formal na atual estrutura e organização não consegue criar cidadãos críticos e atuantes na vida social. Os nossos jovens e adultos, em sua maioria, são desinteressados principalmente nas questões políticas. Criou-se uma cultura de que politicamente todos são iguais, que a 
realidade não vai mudar nunca mesmo. Pouco se faz para diminuir as desigualdades sociais e melhorar a qualidade de vida do conjunto da classe trabalhadora.

Se os nossos jovens estão com essas dificuldades de entendimento é porque de alguma forma nós como educadores, não estamos fazendo com que eles se apropriem do conhecimento necessário para o seu desenvolvimento integral. É importante pontuar que não estamos culpando os professores por este problema, pois falta estrutura física adequada, currículo que atenda de fato as necessidades dos educandos, formação inicial e continuada para os educadores, etc. Ou seja, temos uma escola pública que ainda não é popular. Assim, temos como desafio a ampliação da participação dos trabalhadores nos espaços de decisão, mas isso requer conhecimento teórico e formação políticaorganizativa. A APP-Sindicato dos Trabalhadores em Educação Pública do Paraná, em 2007, iniciou sua escola de formação, uma escola sindical que objetiva formar novos quadros dirigentes e qualificar a luta sindical.

Os cursos de formação são realizados nos vinte e nove núcleos sindicais do Estado do Paraná e apesar das limitações é uma tentativa importante que busca aliar teoria e luta sindical. Citando o ano de 2013 como exemplo, os cursos contribuíram com a participação dos educadores na $\mathrm{CONAE}^{5}$. Em uma das etapas do curso regional, realizou-se uma conferência livre antes das conferências municipais, na qual foram debatidos todos os eixos do documento base o que facilitou a participação e a defesa dos interesses coletivos da categoria, uma vez que já tinham conhecimento dos temas.

A CONAE é um dos espaços em que fica evidente a divergência de interesses entre o público e o privado, ampliar a participação dos trabalhadores em educação pública, nos debates sobre educação e nesses espaços disputar propostas é um grande desafio, pois é a partir dessas discussões que são pensadas as políticas públicas da educação. Uma educação voltada aos interesses dos trabalhadores depende também da participação da classe nesses debates.

O marxismo é um exemplo de como o comunismo resultou da soma de conhecimentos adquiridos pela humanidade.

Vocês leram e ouviram que a teoria comunista, a ciência comunista, criada principalmente por Marx, que esta doutrina do marxismo deixou de ser obra de um socialista apenas, é bem verdade que genial, do século 19, para se transformar na doutrina de milhões e dezenas de milhões de proletários do mundo inteiro, que a aplicam em sua luta contra o capitalismo. E se perguntarem por que a doutrina de Marx pode conquistar milhões e dezenas de milhões de corações na classe mais revolucionária, receberão uma só resposta: porque Marx se apoiava na sólida base dos conhecimentos humanos adquiridos no capitalismo. Ao estudar as leis do desenvolvimento da sociedade humana, Marx compreendeu o inevitável desenvolvimento do capitalismo, que conduz ao comunismo, e, coisa mais importante, demonstrou isso baseando-se exclusivamente no estudo exato, mais detalhado e mais profundo da sociedade capitalista, por ter assimilado plenamente tudo o que a ciência havia descoberto até então. Marx analisou de maneira crítica, sem menosprezar um só ponto tudo o que a sociedade humana criara (LÊNIN, 2005, p. 13-14).

Nesse sentido, Lênin afirma que a cultura proletária só pode ser criada a partir do conhecimento preciso da cultura conhecida pela humanidade em todo o seu desenvolvimento e transformando-a, pois sem esse entendimento não será possível. Ele 
destaca que a cultura proletária tem que ser o desenvolvimento lógico do acervo de conhecimentos acumulados pela humanidade na sociedade capitalista.

Sobre criar uma nova cultura, Gramsci adverte que não significa somente fazer novas descobertas, mas, sobretudo levar ao povo as descobertas já existentes, popularizar o saber. Ressalta que uma multidão de homens pensando coerentemente a realidade é mais importante do que uma descoberta que permaneça em pequenos grupos intelectuais (GRAMSCI, 2004, v. 1, p. 96).

Para Gramsci:

A luta contra a velha escola era justa, mas a reforma não era uma coisa tão simples como parecia; não se tratava de esquemas programáticos, mas de homens, e não imediatamente dos homens que são professores, mas de todo o complexo social do qual os homens são expressão. Na realidade, um professor medíocre pode conseguir que os alunos se tornem mais instruídos, mas não conseguirá que sejam mais cultos (2004, v.2, p. 45).

Ressalta que não existe unidade entre escola e vida, consequentemente, não existe unidade entre instrução e educação. Esse nexo instrução-educação só é representado pelo trabalho vivo do professor quando este é consciente dos contrastes entre a sociedade e a cultura que ele e seus alunos representam.

No que se refere às criticas sobre os métodos de ensino e da velha escola, Lênin diz ser necessário absorver o que ela tem de bom, não imitá-la, não somente assimilar os conhecimentos, mas fazê-los com espírito crítico.

Em lugar do adestramento autoritário que se praticava na sociedade burguesa, contra a vontade da maioria, colocamos a disciplina consciente dos operários e camponeses, que unem a seu ódio contra a velha sociedade o querer, o saber e o estar dispostos a unificar e a organizar as forças para essa luta, a fim de criar, com milhões e centenas de milhões de vontades dispersas, fracionadas e desperdiçadas pela imensa extensão de nosso país, uma vontade única, uma vez que sem ela seremos inevitavelmente vencidos (LÊNIN, 2005, p. 16).

Uma das preocupações de Lênin era justamente fornecer elementos teóricos que pudessem orientar o processo de transformação. Sua formulação teórica ocorre paralelamente com o processo histórico da Revolução Russa, seus escritos tem uma finalidade prática. Essa teoria desenvolvida por Lênin sofre mudanças de acordo com a realidade do processo revolucionário, tanto que, inicialmente ele destaca a importância da repressão militar que vem seguida da repressão administrativa e por último o aspecto organizativo, a capacidade dirigente no processo denominado como a ditadura do proletariado.

Para ele a construção de uma sociedade diferente da sociedade capitalista requer toda uma reorganização e para isso é essencial o conhecimento acumulado pela humanidade. Destaca que o comunismo é uma construção e que "somente sobre a base da instrução moderna poderá criar essa sociedade e, que se carecer dessa instrução, o comunismo não passará de um desejo" (LÊNIN, 2005, p. 18).

A escola para Gramsci (2004, v. 2, p. 19) "é o instrumento para elaborar os intelectuais de diversos níveis", é vista como um espaço de formação de cultura, de construção de hegemonia, cuja função é elevar o nível do senso comum e a concepção de mundo e melhorar as técnicas de trabalho, pois tem o trabalho como princípio educativo. 
Observa-se, uma preocupação em agir para mudar e nesse contexto destaca a importância do conhecimento, do compreender, para que a mudança, de fato, se efetive. Não adianta mudar toda a estrutura se não conseguir mudar o ser humano.

Gramsci defende a ideia de que todos os homens são intelectuais e que os grupos sociais formam seus intelectuais. Um exemplo claro disso vem da educação. Todos os professores são intelectuais por profissão, mas nem todos praticam essa intelectualidade, ou seja, nem todos exercem na sociedade a função de intelectuais. O intelectual mencionado por Gramsci é aquele que atua enquanto dirigente do seu grupo, que é capaz de organizar, de mobilizar.

Segundo Gramsci, os intelectuais podem ser tradicionais, conservadores, que têm como objetivo a preservação das conquistas e valores da classe, a qual pertence, não possuindo, necessariamente uma ligação clara e direta com as classes e nem com as massas. Por sua vez, os orgânicos são militantes engajados, cuja causa é a transformação social, possuem uma leitura de mundo e uma prática que organiza as massas.

De acordo com Gramsci a necessidade de criar intelectuais em níveis mais elevados fez com que ao lado da escola humanista surgissem escolas particulares de diversos níveis. Nesse período histórico "a escola profissional destinava-se às classes instrumentais, enquanto à clássica destinava-se às classes dominantes e aos intelectuais" (GRAMSCI, 2004 , v. 2, p. 33). Para essa divisão ele apontava como solução uma escola única inicial, de cultura geral, humanista e formativa equilibrando o desenvolvimento das capacidades de trabalhar manualmente e intelectualmente. Depois dessa base comum se seguiria a uma escola especializada.

Essa é a escola desinteressada, que não direciona para a profissão. Comparando com a educação dos dias atuais é a que temos hoje até o ensino médio, com exceção dos cursos profissionalizantes em ensino médio, a educação básica não institui nenhuma profissionalização obrigatória, isso só ocorre em nível superior. Uma diferença importante é que a proposta de Gramsci tinha como base a coletividade, a nossa trabalha com base na individualidade, competividade e no atendimento as leis do mercado. Outro destaque de Gramsci (2004, v.2, p. 36) é a importância do currículo escolar em consonância com a idade e o desenvolvimento intelectual nessa escola unitária, uma vez que seria tarefa dela inserir os jovens na atividade social depois de ter elevado a sua maturidade, contando com a capacidade para a criação intelectual, prática e uma autonomia na orientação e iniciativa.

Essa transformação proposta exige mudanças na organização escolar, incluindo reorganização dos métodos de ensino e da distribuição dos anos de vida escolar, na infraestrutura, no material pedagógico e no corpo docente que deve ser ampliado. Gramsci pensava a escola em tempo integral, com dormitórios, refeitórios, biblioteca especializada, entre outros espaços, que proporcionassem vida coletiva diurna e noturna, incluindo estudos coletivos, assistidos pelos professores ou melhores alunos. A pretensão era de trabalhar a disciplina coletiva inclusive nas creches. (2004, v. 2, p. 37).

Segundo Gramsci, "toda escola unitária é escola ativa, embora seja necessário limitar as ideologias libertárias nesse campo e reivindicar com certa energia o dever das gerações adultas, isto é, do Estado, de "conformar" as novas gerações" (GRAMSCI, 2004, v. 2, p. 40). De acordo com Gramsci se dividia em duas fases: escola ativa, onde se busca disciplinar, nivelar, obter um certo conformismo e a escola criadora que se desenvolveria sobre a base da coletivização social, cuja tendência era a expansão da personalidade, já de forma autônoma, responsável com consciência moral e social sólida e homogênea.

De acordo com Lênin (2005), o grande desafio é fazer com que as pessoas tenham consciência coletiva, parem de pensar individualmente e busquem o bem comum. Daí a necessidade da participação ativa da maioria dos trabalhadores na direção da sociedade, do 
Estado e de uma revolução cultural, que seria o acesso da grande massa operária a novos níveis de cultura. No entanto, a dificuldade em resolver essas questões fizeram com que apenas uma vanguarda do proletariado participasse efetivamente desse processo revolucionário. A Revolução Russa da forma como foi idealizada por Lênin, abriria o caminho para uma revolução mundial, mas isso acabou não se efetivando.

O entendimento de Lênin sobre o partido era de que este tinha a função de fazer a luta política e o sindicato a luta econômica, cabendo ao sindicato ultrapassar as lutas economicistas. Ou seja, era necessário dar a luta econômica um caráter político, conseguir a melhoria das condições de trabalho por meio de medidas legislativas e administrativas (2010, p. 125).

Para Gramsci o sindicato antecede o partido e o partido é um elemento na formação da hegemonia da classe operária. O partido político moderno para alguns grupos sociais nada mais é do que o modo de elaborar seus intelectuais orgânicos. E para todos é o mecanismo que desempenha na sociedade civil a mesma função desempenhada pelo Estado. Gramsci traz como função do partido elaborar seus componentes, transformar o grupo nascido e desenvolvido como econômico em intelectuais políticos, qualificados, dirigentes. Ao mesmo tempo em que ele representa, forma o seu grupo (GRAMSCI, 2004, v. 2, p. 24).

De acordo com Gruppi (1986, p. 71), Gramsci se aproximou da compreensão do pensamento de Lênin, e os Cadernos do Cárcere expressam o aprofundamento desse pensamento. Gramsci retomou a concepção de ditadura do proletariado identificando mudanças na estrutura econômica, política, e uma revolução cultural no mundo inteiro.

\section{Os Cadernos utilizados na Formação da APP-Sindicato}

A APP-Sindicato fundada em 1947 como Associação dos Professores do Paraná, unificou-se com duas outras associações de professores em 1981, passando a ser Sindicato em 1989. Seguiu representando os professores do paraná até 1998, quando uniu-se ao SINTE-PR ${ }^{6}$, sindicato que representava os funcionários de escola, passando então a representar todos os trabalhadores em educação pública. Após a unificação, passou a denominar-se: "Sindicato dos Trabalhadores em Educação Pública do Paraná" (Estatuto da APP-Sindicato, 2012, p. 07).

Essa entidade representativa dos educadores ${ }^{7}$ possui uma trajetória de muitas lutas, avanços e dificuldades. Durante os sessenta e sete anos de história foram muitos os desafios enfrentados pela categoria. Diante da necessidade de formação de novos quadros dirigentes criou-se em 2007 a chamada Escola de Formação da APP-Sindicato através do Programa de Formação Político Sindical, em parceria com a Confederação Nacional dos Trabalhadores em Educação - CNTE e a Universidade Federal do Paraná - UFPR (APPSindicato, 2013). O projeto passou por diversas adequações visando atender a demanda sindical e continua sendo desenvolvido até os dias atuais, nos vinte e nove núcleos sindicais da APP-Sindicato.

A teoria é indispensável para que ocorra a transformação social, no entanto ela sozinha sem prática se torna esvaziada de sentido. Portanto, os cadernos utilizados na formação são importantes, mas vale lembrar que o curso de formação não traz somente o estudo dos cadernos, propicia ainda momentos de debate, prática no local de trabalho, além de indicar leituras e sugerir a participação em outras atividades.

Importante salientar que as temáticas e textos utilizados, procuram atender as necessidades teóricas da organização, lembrando que existe uma grande diversidade nos níveis de escolaridade dos cursistas que vai desde o ensino fundamental até o mestrado, são turmas bem heterogêneas, mas que apresentam contribuições de grande relevância. 
O curso teve início em 2007, cujo o projeto inicialmente foi pensado para um triênio, sem a obrigatoriedade do cursista em participar dos três anos. Essa forma de organização permitiu a participação de um grupo maior de sindicalizados, mas fragmentou a formação de boa parte dos participantes, que não concluíram o triênio. Para facilitar a análise da presença das teorias de Lênin e Gramsci nos cadernos dividimos em dois períodos/triênios - 2007-2009 e 2010-2012.

Baseada na proposta de formação da Confederação Nacional dos Trabalhadores em Educação, a formação da APP-Sindicato trouxe para estudo, autores clássicos e contemporâneos nas áreas de sociologia, pedagogia, filosofia, política, economia e história. As temáticas abordadas nos cadernos foram divididas em quatro eixos, conforme o quadro organizado abaixo, sendo que o IV eixo que corresponde aos temas transversais não possui um caderno especifico e os temas foram trabalhados em paralelo aos anteriores.

Temáticas discutidas nos cadernos de formação - triênio 2007-2009

\begin{tabular}{|c|c|c|}
\hline Eixos & Cadernos & Objetivos do eixo \\
\hline 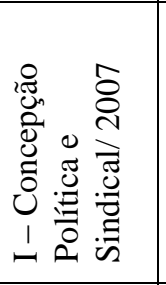 & $\begin{array}{l}\text { Teoria Política; } \\
\text { Economia Política; } \\
\text { Introdução a História do Movimento Sindical; } \\
\text { Movimento Sindical dos Trabalhadores e } \\
\text { Trabalhadoras na Educação no Brasil. }\end{array}$ & $\begin{array}{l}\text { Proporcionar aos dirigentes, uma } \\
\text { fundamentação teórica e metodológica das } \\
\text { concepções e teorias políticas, da história } \\
\text { do movimento sindical e popular com } \\
\text { recorte na organização dos/as } \\
\text { trabalhadores/as da educação no Brasil e } \\
\text { no Paraná }\end{array}$ \\
\hline 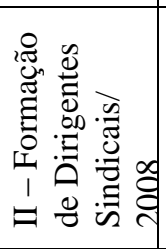 & $\begin{array}{l}\text { Fundamentos da Filosofia: Os caminhos do } \\
\text { "Pensar" para quem quer transformação; } \\
\text { Teoria e Prática da Comunicação Sindical; } \\
\text { Como Fazer Análise de Conjuntura; } \\
\text { Negociação Coletiva e Orçamento Público na } \\
\text { Área de Educação. }\end{array}$ & $\begin{array}{l}\text { Possibilitar a formação política e prática } \\
\text { na preparação dos dirigentes oferecendo } \\
\text { uma formação } \quad \text { metodológica. }\end{array}$ \\
\hline 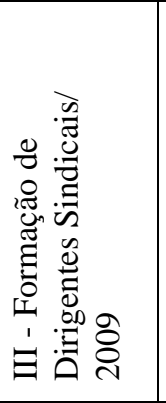 & $\begin{array}{l}\text { A Expressão do Marxismo nos Movimentos } \\
\text { Sociais: A proposta do Fórum Paranaense em } \\
\text { Defesa da Escola Pública; } \\
\text { A Expressão da Filosofia da Libertação nos } \\
\text { Movimentos Sociais: A proposta de escolar do } \\
\text { MST e da APP-Sindicato; } \\
\text { O Impacto das Propostas dos Movimentos } \\
\text { Sindicais e Sociais na Conferência Nacional de } \\
\text { Educação. }\end{array}$ & $\begin{array}{l}\text { Explicitar os fundamentos filosóficos sob } \\
\text { a ótica marxista, da ação sindical e suas } \\
\text { relações com os movimentos sociais. } \\
\text { Estudar o materialismo histórico dialético } \\
\text { afim de direcionar a reflexão para a } \\
\text { atuação sindical, participação no Fórum } \\
\text { Paranaense em Defesa da Escola Pública e } \\
\text { na CONAE. Introduzir a questão } \\
\text { internacionalista abordando o ideário } \\
\text { Latino Americano. }\end{array}$ \\
\hline 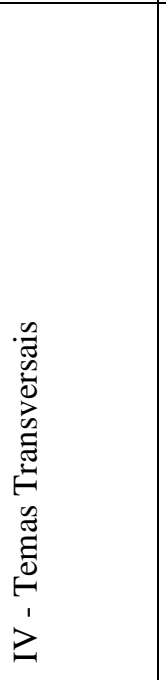 & $\begin{array}{l}\text { Não possui caderno específico. Os Temas } \\
\text { propostos foram: Questão de Gênero; Combate à } \\
\text { todas as formas de discriminação; Meio } \\
\text { ambiente e desenvolvimento sustentável; } \\
\text { Financiamento da Educação - Fundeb; Planos } \\
\text { de Carreira; Fundos de Pensão/ Previdência; } \\
\text { Currículo; } \\
\text { Profissionalização de funcionários; } \\
\text { Formação Continuada; Orçamento Público e a } \\
\text { Educação; Reforma Sindical, Trabalhista e os } \\
\text { Trabalhadores em Educação; Alca, Mercosul a } \\
\text { Acordos Gerais de Livre Comércio; } \\
\text { Reestruturação Produtiva } \\
\text { Neoliberalismo, Estado Mínimo e Serviço } \\
\text { Público; Capacitação de membros de Conselhos } \\
\text { Municipais e Estaduais de Educação e demais } \\
\text { Conselhos; Outros }\end{array}$ & $\begin{array}{l}\text { Abordar temas fundamentais para a } \\
\text { emancipação da classe trabalhadora e para } \\
\text { a construção de uma sociedade socialista. } \\
\text { Entre os temas propostos, abordaremos a } \\
\text { questão de gênero, o combate à todas as } \\
\text { formas de discriminação, a questão } \\
\text { ambiental, a luta internacional da classe } \\
\text { trabalhadora, entre outros temas. }\end{array}$ \\
\hline
\end{tabular}


Dos cadernos trabalhados em 2007, dois deles fazem referências a Gramsci. O caderno sobre Teoria Política apresenta outros autores, de Gramsci especificamente trata da compreensão de Estado ampliado na perspectiva de sociedade civil e política, a definição de hegemonia e a importância da ideologia e de uma educação revolucionária para que se obtenha uma hegemonia que reflita os interesses da classe trabalhadora. De forma sintética aborda ainda os intelectuais orgânicos, guerra de movimento e guerra de posição, a crise da hegemonia e o partido político.

Os anexos desse caderno trazem o texto, "Para uma teoria do conhecimento em Gramsci", de Giovanni Semeraro, um pouco mais extenso que situa o leitor na realidade vivenciada por Gramsci e seu envolvimento político na luta da classe trabalhadora. Aborda a questão da ciência, da filosofia da práxis e da ideologia na construção do conhecimento.

No caderno Introdução à História do Movimento Sindical, encontramos o texto da Andréa Caldas, "Educadoras(es) e militantes de "carne e osso": alguns apontamentos para o debate", que objetivando trazer a reflexão a questão da organização dos trabalhadores e sua relação com a práxis política e educativa, tem como referência as seguintes obras de Gramsci: Os escritos políticos; Os intelectuais e a organização da cultura; Maquiavel, a política e o estado moderno; Concepção dialética da história.

O Eixo 2: Formação de Dirigentes Sindicais, (correspondente ao ano de 2008) trabalha com a filosofia, a comunicação, a conjuntura e a negociação coletiva, visando contribuir na atuação do dirigente. O caderno "Fundamentos da Filosofia: Os caminhos do 'Pensar' para quem quer transformação", não traz diretamente para a discussão textos de Lênin e Gramsci, no entanto, nas referências está citada a obra: Os intelectuais e a organização da cultura, de Gramsci.

O caderno, Teoria e Prática da Comunicação Sindical, apresenta a comunicação na disputa pela hegemonia, sendo esta uma ferramenta fundamental nos embates de classes, uma vez que se apresenta como contraposição a comunicação de massa, que objetiva difundir os valores de classe dominante, no intuito de manter a hegemonia. Trata da hegemonia, comunicação e ação revolucionária segundo Lênin e Gramsci, a partir das seguintes obras de Lênin: O que fazer; Por onde começar; Informação de classe e o artigo o problema essencial; de Gramsci foi utilizado a concepção dialética da história.

No ano de 2009, cujo título do caderno é "Expressão da Filosofia da Libertação nos Movimentos Sociais: a proposta da escola do MST e da APP-Sindicato", o texto: Educação, Filosofia e Escola, retomou o conceito de hegemonia em Gramsci pensando o processo revolucionário através da articulação entre política, educação e cultura, sendo referenciado o caderno 12 - Apontamentos e notas esparsas para um conjunto de ensaios sobre a história dos intelectuais.

Sintetizando: no triênio 2007-2009, foram estudados onze cadernos no curso de formação. Ao analisar os escritos dos cadernos não encontramos textos clássicos, no entanto, os autores dos cadernos mencionam nas referências as seguintes obras clássicas: de Marx/ Marx e Engels: Elementos Fundamentales para la Crítica de la Economia Política (Grundisse); A ideologia Alemã; Teses sobre Feurbach; Manifesto do Partido Comunista; O Capital: Crítica da Economia Política - Livro I; Contribuição à Crítica da Economia Política; A introducción general a la crítica de la economia política/ 1857 y otros escritos sobre problemas metodológicos; Prólogo a contribución crítica de la economía política em introducción general a la crítica de la economia política/ 1857 y otros escritos sobre problemas metodológicos; El Capital; La sagrada familia y otros escritos filosóficos de la primera época; Sindicalismo. De Gramsci: Caderno 12, Apontamentos e notas esparsas para um conjunto de ensaios sobre a história dos intelectuais; Os intelectuais e a 
organização da cultura; Maquiavel, a política e o estado moderno; Os escritos políticos; Concepção Dialética da História. De Lênin: Informação de Classe, O Estado e a Revolução,

Para entender como a escolarização se constituiu na forma como vemos hoje, é necessário conhecer como se deu o processo de construção da sociedade, qual o papel do Estado, da gestão e do sindicato nesse contexto. Estes foram os temas centrais presentes nos cadernos utilizados no triênio 2010-2012.

\section{Temáticas discutidas nos cadernos de formação - triênio 2010-2012}

\begin{tabular}{|c|c|c|}
\hline Eixos & Cadernos & Objetivos do eixo \\
\hline 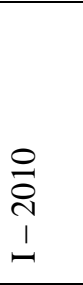 & $\begin{array}{l}\text { Escola e Desigualdade Social; } \\
\text { Capitalismo, Estado e Desigualdade: Impactos na } \\
\text { Política Educacional; } \\
\text { A Desigualdade Educacional por Dentro da Escola. }\end{array}$ & $\begin{array}{l}\text { Refletir sobre as desigualdades e } \\
\text { entender como estas refletem no espaço } \\
\text { escolar. Ampliar a consciência dos } \\
\text { educadores levando-os a assumir um } \\
\text { papel social e politico, a tomar partido } \\
\text { e deixar de lado a omissão } \\
\text { compreendendo melhor a realidade. }\end{array}$ \\
\hline 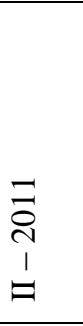 & $\begin{array}{l}\text { As Concepções Teóricas, Ideológicas e Pedagógicas da } \\
\text { Sociedade e da Escola e seus Impactos na Gestão do } \\
\text { Estado; } \\
\text { A Formação da/o Dirigente e Gestão Democrática. As } \\
\text { elaborações e Concepções Teóricas e Pedagógicas para } \\
\text { a Sociedade e Escola no Campo da Tradição Marxista; } \\
\text { O Modernismo e o Pós-Modernismo no Contexto do } \\
\text { Mundo do Trabalho e da Educação. }\end{array}$ & $\begin{array}{l}\text { Formar para organizar, aprofundar a } \\
\text { discussão sobre a sociedade, o } \\
\text { individua e a educação que temos e } \\
\text { queremos, ampliar a capacidade de } \\
\text { participação, intervenção e organização } \\
\text { dos educadores na escola, nos } \\
\text { movimentos sociais e na vida. }\end{array}$ \\
\hline 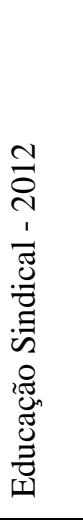 & $\begin{array}{l}\text { Tema I: Como Funciona a Sociedade Capitalista; } \\
\text { Tema II: Processo de Consciência da Classe } \\
\text { Trabalhadora; } \\
\text { Tema III: O ABC DO SINDICATO - PARTE I: } \\
\text { Concepção, Estrutura e Organização Sindical; O } \\
\text { Projeto Político-Sindical-Educacional da APP- } \\
\text { Sindicato; } \\
\text { Tema IV: I: O ABC DO SINDICATO - PARTE II: } \\
\text { Conheça seus Direitos - A Carreira e a Valorização } \\
\text { dos/as Trabalhadores/as em Educação; } \\
\text { Tema V: Condições de Trabalho, Saúde e a Luta dos/as } \\
\text { Trabalhadores em Educação; } \\
\text { Tema VI: A Escola que Queremos. }\end{array}$ & $\begin{array}{l}\text { Ampliar a consciência dos educadores } \\
\text { na perspectiva da construção de uma } \\
\text { sociedade sem exclusão e democrática. }\end{array}$ \\
\hline
\end{tabular}

Fonte: cadernos de formação e Site da APP-Sindicato. Organização dos autores.

Os textos dos cadernos têm por objetivos ajudar a entender e refletir sobre o processo de consciência e o pensar a escola a partir da realidade da constituição da sociedade e do Estado. Os textos partem da realidade do Paraná, avançando para o Brasil e a América Latina. Nos cadernos utilizados em 2010, observamos uma grande diversidade de autores e embora não se tenha nenhum texto clássico de Marx, Lênin, Gramsci ou Mészáros, através da leitura do texto encontramos as concepções marxistas presentes.

As bases teóricas e as reflexões dos cadernos de 2011 continuaram abordando a sociedade, o indivíduo e a educação. Educação definida como o processo de formação completa da pessoa, na qual a escolarização tem um papel importante. Além dos textos, o caderno I, traz um quadro com a síntese das concepções e tendências da educação e suas manifestações na prática escolar que ajudam os educadores a reconhecer as bases de suas práticas pedagógicas.

O caderno II traz as reflexões sobre as teorias de Gramsci e Freire, procurando relacioná-las com a gestão e finalidade da escola, a fim de melhorar o entendimento sobre 
a organização escolar e propiciar novas formas de intervenção, priorizando uma gestão democrática e participativa. Compõe este caderno os seguintes artigos: Política $e$ Educação em Gramsci (reflexões a partir dos escritos de 1916 a 1918), o qual analisa alguns artigos sobre educação escritos por Gramsci no período mencionado. O texto apresenta a conjuntura italiana e trata da política, educação e gestão, além da proposição de novas alternativas culturais para se organizar uma cultura popular.

Já o texto A gestão da educação pela perspectiva de Gramsci, utiliza como categoria de análise a gestão da educação a partir dos conselhos de fábrica, tratando da concepção de mundo, hegemonia, processo de formação do homem, educação, escola, ética, cultura, sociedade política e sociedade civil, ou seja, de elementos centrais nas formulações gramsciana.

Nos cadernos de 2012, o primeiro traz reflexões sobre a organização e a exploração na sociedade capitalista, com os seguintes textos: $O$ capitalismo, por Ernest Mandel, $O$ trabalho e seus sentidos, de Ricardo Antunes, Manifesto do Partido Comunista, de Marx e Engels, Atualidade da Teoria Leninista da Organização à Luz da Experiência Histórica, de Ernest Mandel. O Segundo é um caderno mais histórico sobre a luta dos trabalhadores, organização e estrutura sindical. O Terceiro faz referência as condições de trabalho e saúde e qual escola queremos.

Em síntese, no triênio 2010-2012, foram estudados nove cadernos, dentre as obras clássicas que serviram de referências aos textos publicados nos cadernos, destacamos: de Marx: O capital, O 18 de Brumário, Manuscritos Econômicos e Filosóficos, A Ideologia Alemã, o Capítulo IV de O Capital e o Manifesto do Partido Comunista; de Gramsci: A Concepção Dialética da História, Sindicatos e Conselhos, Escritos Políticos, Caderno do Carcere 12, Os intelectuais e a Organização da Cultura, Quaderni del Carcere, Scritti Giovanili, Cronache Torinese; de Lênin: Situação Revolucionária.

Ao analisar o conteúdo dos cadernos, ainda que de forma inicial, podemos constatar a importância das obras de Lênin e Gramsci na construção dos textos elaborados para a proposta de formação política da APP-sindicato. Todavia, chamamos a atenção para a necessidade de o material explorar mais diretamente os textos dos próprios autores, ao invés de utilizar-se apenas de intérpretes.

\section{Algumas considerações}

Tanto Lênin quanto Gramsci analisavam o processo histórico buscando a partir de suas realidades encontrar alternativas para a transformação social. Entendem a revolução como um processo a ser construído. Ambos enfatizaram a importância da escola e se empenharam para melhorá-la, pois viam nela um instrumento para a transformação social.

Estamos cientes de que as teorias revolucionárias desenvolvidas por Lênin e Gramsci foram pensadas a partir das experiências vivenciadas por eles, na tentativa da construção de uma sociedade diferente, da qual viviam. Tais teorias não podem ser aplicadas da mesma forma, como foram no passado, pois vivemos em um período histórico distinto daquele, com características próprias, no entanto, é indispensável conhecer a realidade em que estamos vivendo e nos apropriarmos das experiências acumuladas pela humanidade para construirmos a transformação social.

$\mathrm{O}$ grande desafio que encontramos enquanto educadores e sindicalizados é o despertar de consciência dos trabalhadores, principalmente da educação, de que devemos lutar, mas não apenas pelos nossos interesses imediatos e individuais, mas sim que esta deve ser uma luta mais ampla pelos interesses da sociedade e de todo o povo.

Com o objetivo de avançar nesse processo a APP-sindicato criou uma escola de formação política para fortalecer a luta da categoria e sua consciência, enquanto classe 
trabalhadora. O programa de formação passou por adequações no decorrer do tempo com o intuito de melhorar a qualidade, atender a demanda e ampliar a consciência dos educadores para que assumam um papel social e político. Ao compararmos o projeto finalizado em 2012, com o iniciado em 2007, identificamos uma diminuição no número de cadernos e uma alteração na forma de organização. Entre 2007 e 2009 era um caderno por etapa, sendo que eles tinham como características textos curtos e muitas questões para o debate. No período de 2010 a 2012 foram apenas três cadernos por ano para seis etapas presenciais de formação, contendo textos mais longos e de maior aprofundamento teórico. Uma característica encontrada na maioria dos cadernos, é a utilização de poemas ou frases, que retratam a realidade humana e proporcionam reflexões.

$\mathrm{Na}$ proposta, as questões e textos estudados foram pensados como um início do processo de formação, pois eram bastante gerais, seu aprofundamento dependeu de cada pessoa e das leituras que cada um fez, a partir da base inicial, uma vez que cada pessoa é diferente e abstrai as informações de acordo com sua visão de mundo e das experiências vivenciadas até então.

Entendemos que é uma responsabilidade dos trabalhadores em educação elevar os níveis de cultura do povo e subsidiar teoricamente o processo de transformação social. No entanto, só obteremos êxito se tivermos consciência de classe, se pensarmos e agirmos coletivamente. A grande questão é: os trabalhadores já estão com um nível de consciência e com vontade de fazer acontecer a transformação social?

Simplesmente dizer, que a educação, na forma como está constituída, não atende aos seus objetivos nos parece um grande equívoco. Primeiramente se faz necessário saber qual o objetivo, a estrutura educacional atual, e, posteriormente quais os nossos anseios enquanto classe trabalhadora para a educação. Se o nosso anseio for por uma educação desinteressada, conforme a defendida por Lênin e Gramsci, com formação do ser humano de forma integral e com o intuito de promover a transformação social, podemos sim dizer, que dá forma como se constitui dificilmente obteremos êxito.

Precisamos de mudanças profundas na educação que vão desde a reformulação do currículo, de melhorias na infraestrutura, na prática educativa, na formação inicial e continuada dos educadores, etc. Atualmente trabalhamos com um currículo fragmentado. A separação em níveis de ensino, dificuldade de diálogo e trabalho integrado entre os níveis, que vão desde a pré-escola a pós-graduação, refletem a ausência de articulação, a qual dificulta a construção de um currículo que atenda de fato a demanda da classe trabalhadora e possibilite a transformação social. Ao que nos parece continuamos educando para o mercado de trabalho e não para a formação do ser humano integral e ainda não conseguimos romper com a velha forma de exploração da sociedade capitalista. Educamos para a individualidade mesmo sabendo que, enquanto ser social, nos construímos através das relações que estabelecemos em sociedade.

É possível sonhar com uma sociedade justa e igualitária, no entanto, a realidade atual expressa a distância que estamos, para alcançarmos esse objetivo. Daí a necessidade e importância de retomarmos os clássicos (Marx, Lênin e Gramsci), para revigorar nossos compromissos com a educação e qualificar a formação política dos nossos educadores. Diante disso, entendemos que o fortalecimento da Escola de Formação Política da APPSindicato é uma forma de acelerar e iluminar esse sonho. 


\section{Referências}

ANJOS, Amâncio Luiz Saldanha dos. APP-Sindicato - 60 anos. Cascavel e região - 40 anos: História e memórias. Cascavel: ASSOESTE, 2008, 174p.

APP - Sindicato dos Trabalhadores em Educação Pública do Paraná. Estatuto. Curitiba, 2012.

APP - Sindicato dos Trabalhadores em Educação Pública do Paraná. Caderno I: Escola e Desigualdade Social. Curitiba, 2010, 59p.

APP - Sindicato dos Trabalhadores em Educação Pública do Paraná. Caderno II: Capitalismo, Estado e Desigualdade: Impactos na Política Educacional. Curitiba, 2010, 94p.

APP - Sindicato dos Trabalhadores em Educação Pública do Paraná. Caderno III: A Desigualdade Educacional por dentro da Escola. Curitiba, 2010, 102p.

APP - Sindicato dos Trabalhadores em Educação Pública do Paraná. Caderno I: As concepções teóricas, ideológicas, e pedagógicas da sociedade e da escolar e seus impactos na gestão do Estado. Curitiba, 2011, 90p.

APP - Sindicato dos Trabalhadores em Educação Pública do Paraná. Caderno II: A formação dalo dirigente e gestão democrática. As elaborações e concepções teóricas $e$ pedagógicas para a sociedade e escolar no campo da tradição marxista. Curitiba, 2011, $114 \mathrm{p}$.

APP - Sindicato dos Trabalhadores em Educação Pública do Paraná. Caderno III: $O$ modernismo e o pós-modernismo no contexto do mundo do trabalho e da educação. Curitiba, 2011, 50p.

APP - Sindicato dos Trabalhadores em Educação Pública do Paraná. Caderno I projeto 2012/2014 Curso de Educação Sindical, Curitiba: APP-Sindicato, 2012, 70 p.

APP - Sindicato dos Trabalhadores em Educação Pública do Paraná. Caderno II projeto 2012/2014 Curso de Educação Sindical, Curitiba: APP-Sindicato, 2012, 88 p.

APP - Sindicato dos Trabalhadores em Educação Pública do Paraná. Caderno III projeto 2012/2014 Curso de Educação Sindical, Curitiba: APP-Sindicato, 2012, 63 p.

APP - Sindicato dos Trabalhadores em Educação Pública do Paraná. A Expressão do Marxismo nos Movimentos Sociais: A Proposta do Fórum Paranaense em Defesa da Escola Pública: Programa de Formação da CNTE/ APP-Sindicato/ UFPR: Um novo conceito de atuação sindical. Fascículo 2, Curitiba: World Laser, 2009, 90 p.

APP - Sindicato dos Trabalhadores em Educação Pública do Paraná. A Expressão da Filosofia da Libertação nos Movimentos Sociais: A Proposta de Escola do MST e da APPSindicato: Programa de Formação da CNTE/ APP-Sindicato/ UFPR: Um novo conceito de atuação sindical. Fascículo 3, Curitiba: World Laser, 2009, 86 p.

APP - Sindicato dos Trabalhadores em Educação Pública do Paraná. Projeto de Formação Político Sindical - APP-Sindicato, publicado em 12 de março de 2007 no endereço: <http://www.appsindicato.org.br/include/paginas/noticia.aspx?id=1005> Acesso em $21 \mathrm{de}$ abril de 2013.

DIEESE. Negociação Coletiva e Orçamento Público na Área de Educação: Programa de Formação da CNTE/ APP-Sindicato/ UFPR: Um novo conceito de atuação sindical. Brasília, DF: Confederação Nacional de Trabalhadores em Educação, 2008, 56 p.

GOETTERT, Jones Dari. Introdução à história do movimento sindical: Programa de Formação da CNTE/ APP-Sindicato/ UFPR: Um novo conceito de atuação sindical. 2. ed. Brasília, DF: Confederação Nacional de Trabalhadores em Educação, 2007, 91 p.

GRAMSCI, Antonio. Cadernos do Cárcere, volume 1, Tradução: Carlos Nelson Coutinho. 3. ed. Rio de Janeiro: Civilização Brasileira, 2004. 
GRAMSCI, Antonio. Cadernos do Cárcere, volume 2, Tradução: Carlos Nelson Coutinho. 3. ed. Rio de Janeiro: Civilização Brasileira, 2004.

GRAMSCI, Antonio. Cadernos do Cárcere, volume 3, Tradução: Carlos Nelson Coutinho. 3. ed Rio de Janeiro: Civilização Brasileira, 2002.

GRUPPI, Luciano. Tudo começou com Maquiavel - as concepções de Estado em Marx, Engels, Lênin e Gramsci. 7 ed. Rio Grande do Sul: L\&PM Editores LTDA, 1986.

JINKINGS, Ivana; SADER, Emir. As armas da crítica: antologia do pensamento de esquerda: clássicos. São Paulo: Boitempo, 2012. 300p.

LÊNIN, Vladimir Ilitch. As tarefas da juventude na construção do socialismo. São Paulo: Expressão Popular, 2005.

LÊNIN, Vladimir Ilitch. Que fazer: problemas candentes de nosso movimento. São Paulo: Expressão Popular, 2010. 288p.

MACIEL, João Orlando Flores. Economia Política: Programa de Formação da CNTE/ APP-Sindicato/ UFPR: Um novo conceito de atuação sindical. 2. ed. Brasília, DF: Confederação Nacional de Trabalhadores em Educação, 2007, 84 p.

MONLEVADE, João Antonio Cabral de. Movimento Sindical dos Trabalhadores $e$ Trabalhadoras em Educação no Brasil. 2. ed. Brasília, DF: Confederação Nacional de Trabalhadores em Educação, 2007, 94 p.

PASSOS, Luiz Augusto. Fundamentos de Filosofia. Os caminhos do "pensar" para quem quer transformação: Programa de Formação da CNTE/ APP-Sindicato/ UFPR: Um novo conceito de atuação sindical. Brasília, DF: Confederação Nacional de Trabalhadores em Educação, 2008, 129 p.

SANTIAGO, Claudia. GIANNOTTI, Vito. Teoria e Prática da Comunicação Sindical: Programa de Formação da CNTE/ APP-Sindicato/ UFPR: Um novo conceito de atuação sindical. Brasília, DF: Confederação Nacional de Trabalhadores em Educação, 2008, 95 p. SANTIAGO, Claudia. MORAES, Reginaldo Carmello de. Como fazer uma análise de conjuntura: Programa de Formação da CNTE/ APP-Sindicato/ UFPR: Um novo conceito de atuação sindical. Brasília, DF: Confederação Nacional de Trabalhadores em Educação, 2008, $81 \mathrm{p}$.

SILVEIRA, Alair Suzeti da. Teoria Política: Programa de Formação da CNTE: Um novo conceito de atuação sindical. 2. ed. Brasília, DF: Confederação Nacional de Trabalhadores em Educação, 2007, 73 p.

Notas

\footnotetext{
${ }^{1}$ Mestranda em Educação na Unioeste, campus de Francisco Beltrão. E-mail: denilacoelho@ hotmail.com

2 Professor do Colegiado de Pedagogia e do Mestrado em Educação da Unioeste - Campus de Francisco Beltrão - PR. Membro do Grupo de Pesquisa: História, Sociedade e Educação no Brasil - HISTEDOPR GT local do HISTEDBR. Historiador e mestre em Educação pela UFMT, Doutor em Educação pela UFSCar e Pós-doutor na área de Filosofia e História da Educação pela UNICAMP. Email: andrecastanha66@gmail.com

${ }^{3}$ Comunista vem da palavra latina communis e significa comum. A sociedade comunista significa que tudo é comum: a terra, as fábricas, o trabalho (LENIN, 2005, p. 26).

${ }^{4}$ Para efeito desse artigo a utilização da palavra escola trata especificamente da instituição formal e a escola de formação se refere ao espaço de formação político sindical da APP-Sindicato.

${ }^{5}$ Conferência Nacional de Educação.

${ }^{6}$ Sindicato dos Trabalhadores na Educação Pública do Paraná.

${ }^{7}$ A utilização da palavra educadores é baseada no entendimento de que sendo a escola um espaço educativo, todas as pessoas que fazem parte desse conjunto educam e são educadas.
} 